\title{
RITOS DE PASAJE ENTRE LOS MAYAS ANTIGUOS
}

\author{
EnRIQUe Bonavides Mateos \\ CEM, IIF, UNAM
}

Cuando se aborda el estudio de una religión nos encontramos con el hecho de que el hombre desarrolla su existencia en dos tiempos diferentes: el primero es el tiempo lineal, que podemos denominar profano, en el cual tienen lugar nuestras actividades cotidianas y que puede ser interrumpido por un tiempo corto o sagrado que transcurre fuera de la realidad, y por tanto tiene un significado simbólico que funciona como complemento de la misma. Para que exista una conexion entre el tiempo profano y el sagrado, es necesario que el hombre efectúe una serie de actos simbolicos que denominamos "rito".

Toda ceremonia ritual religiosa se divide en varias etapas, cada una de las cuales es un rito en sf misma:
a) separación del medio profano
b) incorporación al medio sagrado
c) separación del medio sagrado
d) reincorporación al medio profano

El rito se conforma de acciones mágicas de imitación o de contacto mezcladas entre sí.

Por su acción los ritos pueden dividirse en indirectos, que provocan efectos mediatos y los directos que producen efectos inme- 
diatos y automáticos; a su vez las etapas rituales se dividen en negativas y positivas, las primeras conforman la preparacion del rito y comprenden la purificacion de todos los elementos que lo integran.

Los rituales responden a patrones mágico-religiosos preestablecidos ya sea por las necesidades ideologicas, economicas, politicas, sociales o psiquicas, por lo que deben abordarse por todos y cada uno de estos puntos de vista si es que se quiere comprender totalmente el papel de los mismos en la sociedad, es por ello que si queremos analizar un rito, hay que partir del hecho de que toda ceremonia de este tipo es una parte activa y necesaria de todo desarrollo cultural, así como medio de cohesion social.

Hay que analizar el significado sociologico de las diversas formas de la expresión religiosa, complementando el estudio con la ayuda de un método fenomenológico sin olvidar el estudio de las causas y consecuencias de la expresión religiosa.

Una de las clasificaciones más apropiadas para entender el ritual es la que nos presenta Van Gennep, quien explica que existen tres tipos de ritos:

a) ritos de separacion

b) ritos de transición o de pasaje

c) ritos de incorporación ${ }^{1}$

Los ritos de separación implican la muerte simbolica de quien los sufre; los ritos de transición son los más complejos y los más variados, dentro de los cuales se encuentra la mayoría de los ritos de iniciación, ya sean colectivos 0 individuales; también pertenecen a este tipo de ceremonias diversos rituales del ciclo de vida y se caracterizan principalmente por que el individuo que los realiza, cambia su función simbolica y social en su grupo, con lo cual adquiere diferentes responsabilidades, derechos y obligaciones; los ritos de incorporación implican la adquisición simbolica de un protector o ancestro familiar, clánico o tribal, como ejemplo tene-

${ }^{1}$ Van Gennep (1960) 
mos los ritos matrimoniales en los cuales un grupo acepta la entrada de un extraño, por lo cual deja de ser protegido por su anterior ancestro y pasa a serlo del ancestro del grupo que lo recibe, es por eso que este tipo de rituales en su gran mayorfa no son retroactivos.

Toda ceremonia ritual religiosa conforma un puente de contacto entre el hombre y sus deidades, es por eso que deben efectuarse los pasos de la misma con toda la perfección posible, pues un error implicaría una ofensa a sus entidades religiosas o el rompimiento de un orden establecido.

La primera etapa de todo ritual consta de una preparacion formada por prohibiciones en general, ya sean de tipo sexual, alimenticio o de cualquier otro que implique básicamente purificación, cuyos perfodos de duración varían de acuerdo a la importancia de la ceremonia y sus consecuencias dentro de la sociedad.

La observancia de la pureza ritual es necesaria pues al entrar al dominio de lo sagrado, los participantes entran también en el de los dioses y por lo tanto están bajo su protección, eso implica que el hombre puede ser purificado si está impuro o manchado y a la vez, si ha estado en contacto con lo sagrado, también está cargado de impurezas, por ello desde el momento en que un niffo nace, se le considera - desde el punto de vista simbolico- impuro con respecto al medio que lo recibe y eso se debe a que lo sagrado implica pureza e impureza al mismo tiempo, es decir, tiene dos valencias que conforman el interés religioso humano.

Los ritos del ciclo de vida del maya prehispánico conforman una unidad simbolica desde los ritos prenatales hasta los funerarios, y los más importantes a mi parecer son los que se analizan en el transcurso del presente trabajo.

Para llevar a cabo la conservación y fomento de la vida, el hombre concibe la ingerencia de personajes o fuerzas sobrenaturales, con las que el individuo o la comunidad se esfuerzan por establecer relaciones rituales, a fin de proteger y propiciar las diferentes etapas de la existencia de un individuo. 
Las mujeres mayas al pedir el buen nacimiento de sus hijos, acompañaban sus rezos con ofrendas a los dioses. ${ }^{2}$

En Guatemala las parejas que no tenían hijos se autosangraban varias partes del cuerpo o sacrificaban algunas aves, pidiendo a sus dioses la dicha de tener descendencia, y cuando no lograban su objetivo acudían a las hechiceras quienes:

"mandaban hacer penitencia... que apartasen cama, marido y mujer; por espacio de cuarenta días, que no comiesen cosa con sal, que comiesen pan seco o solo maíz, o que estuviesen tantos en el campo metidos en alguna cueva, que les señalaban, que durmiesen sobre la tierra desnuda. Todo esto hacían porque sus Dioses se aplacacen y les diesen hijos". ${ }^{3}$

En las sociedades agrícolas es muy importante para una familia contar con la mayor cantidad posible de hijos, pues significan por una parte una mayor fuerza de trabajo y por otra un fortalecimiento de la comunidad; estas serían algunas de las causas por las que los hijos eran considerados como un don de los dioses.

En algunas religiones, el ayuno y la abstención sexual son prácticas ascéticas que refieren al dominio del cuerpo y se practican con fines religiosos o sociales. En el terreno religioso la ascesis puede obedecer a una infravaloración del cuerpo, muchas veces

considerado como la prisión del alma, o bien el ascetismo es a veces un medio para propiciar a la divinidad y entrar en el ámbito de lo sagrado; puede ser una práctica expiatoria ya sea privada o comunitaria, por lo que podemos decir que en el pensamiento religioso, en algunas circunstancias, la no satisfacción de ciertas necesidades corporales hace inmanente lo sagrado.

Es probable que para los antiguos mayas el ayuno implicara ofrenda o purificación, y que la abstención sexual, como sacrificio personal fuera uno de los factores que eliminara el impedimento de la procreación; por otra parte, tal vez identificaron el poder re-

\footnotetext{
${ }^{2}$ Landa (1978:58)

${ }^{3}$ Ximénez (1930:vol. I:89)
} 
generativo de la tierra con la fertilidad y asf la entrada y permanencia en la cueva probablemente, haya sido un rito que simbolizara la entrada al hogar de Chac que, como dios del agua es dios de vida y lograr con ello un renacimiento simbolico, una transformación que propiciara el nacimiento del futuro hijo. Hay que recordar que en la antigüedad, en varias civilizaciones se efectuaba el mismo ritual de entrada a la cavema y con los mismos intereses. ${ }^{4}$

En Yucatán en los momentos previos al parto, una mujer, a la que Landa define como "hechicera", colocaba debajo del lecho de la parturienta la imagen de Ixchel, la diosa del alumbramiento. ${ }^{5}$

El factor mágico se da sobre la base de que lo semejante produce lo semejante por lo que Ixchel pudo haber sido una diosa de la fertilidad y es probable que la colocación de su imagen fuera acompañada de rezos pidiendo un parto sin problemas. Hay que recordar que Ixchel era también la diosa del tejido, la medicina y la adivinación en Yucatán. ${ }^{6}$

Los atributos religiosos de Ixchel nos hacen pensar en ella como una diosa lunar que, como regidora del ciclo menstrual, se asocia al ciclo generativo femenino. En el estudio de Thompson sobre las deidades lunares en Mesoamérica, se dan las características comunes de estas diosas, mismas que en su mayoría se cumplen en la figura de la diosa yucateca. ${ }^{7}$ En conclusión podemos decir que Ixchel, como diosa de la Luna actuaba, entre otras potencialidades, como diosa de la procreación entre los mayas de Yucatán.

En algunas ocasiones las mujeres próximas al parto se confesaban ante el sacerdote, médico o marido, quienes después se lo decran a sus parientes y cuando había dificultades en el parto se confesaban tanto la mujer como el marido, confesión que no tenía los mismo fines que la cristiana, ya que se confesaban para evitar la

${ }^{4}$ Eliade (1975 b:220-242)

${ }^{5}$ Landa (1978:58)

${ }^{6}$ Roys (1972:77)

7 Thompson (1939:24-29) 
muerte, la enfermedad o una desgracia economica. Las faltas que confesaban eran fundamentalmente el robo, el homicidio, las faltas sexuales y la mentira.

La confesion se consideraba como medio de purificacion de las malas acciones cometidas.

Según Landa:

Que los yucatanenses naturalmente conocían que hacían mal, y porque creían que por el mal y pecado les venían muertes, enfermedades y tormentos, tenían por costumbre confesarse cuando ya estaban en ellos. De esta manera, cuando por enfermedad u otra cosa estaban en peligro de muerte, confesaban sus pecados y si se descuidaban traíanselos sus parientes más cercanos o amigos a la memoria, y así decían públicamente sus pecados: al sacerdote si estaba allí, y si no, a los padres y madres, las mujeres a los maridos y los maridos a las mujeres... Los pecados de que comúnmente se acusaban era el hurto, homicidio, de la carne y falso testimonio y con esto se creían salvos. ${ }^{8}$

La confesión como acción purificadora se confirma también en Guatemala durante la Colonia, asi, cuando la comunidad reconocía sus faltas a los dioses, el pueblo se reunía, buscaba a la mujer más vieja y decrépita que hubiera y la llevaba al campo, situándola en un cruce de caminos, donde la rodeaban todos y confesaban públicamente sus faltas; posteriormente, el sacerdote mataba a la anciana con una piedra golpeándola en la cabeza y luego todos los confesantes la cubrían con piedras erigiendo asi un gran túmulo; al terminar regresaban a sus casas, convencidos de que todas sus faltas habían sido expiadas y que el pueblo estaba purificado. ${ }^{9}$

En Guatemala poco antes del parto, las mujeres tomaban una mezcla de "chile, cordoncillo y otros brebajes que llamaban suchiles"10 para evacuar la placenta. En el momento del parto colocaban una piedra caliente sobre el vientre de la madre para una mejor expulsión del producto. Al nacer el niño, sus padres lo baña-

${ }^{8}$ Landa (1978:47)

${ }^{9}$ López Medel (1941:226)

${ }^{10}$ Fuentes y Guzmán (1969:vol. I:217) 
ban en el río más cercano a su vivienda; también arrojaban los instrumentos utilizados durante el parto, así como la piedra con que habian calentado el vientre matemo y ofrecían sacrificios a sus dioses. ${ }^{11}$

El mismo Torquemada dice:

Cuando lavaban la criatura, hacían sus sacrificios de incienso y papagayos; éste hacían en fuente o manantial, la mejor que hallaban; y si no la había, se iban a un río y en alguna parte más sefialada y acomodada de sus corrientes (en especial a la que hacía algún salto o tumbo) hacían este sacrificio. Todos los vasos y cosas que habían servido el día que nació la criatura, y juntamente una piedra, con que solían calentar el vientre de la mujer parida. Todo lo dedicaban para aquel sacrificio y lo ofrecían a las aguas de la fuente o río donde el sacrificio se hacía. ${ }^{12}$

Tanto en Guatemala como en Yucatán cuando nacía un nifio, su padre o el sacerdote sacrificaba una gallina blanca dando gracias a los dioses por el nacimiento de la criatura; ${ }^{13}$ durante nueve dfas sacrificaban gallinas blancas en un templo "donde quedaban por obvención de sus sacerdotes aquellas aves",14 y se ofrecían convites en los que participaban los principales, los parientes y los amigos de los padres.

En Guatemala, el sacerdote mayor echaba suertes para saber el día en que se debía cortar el cordón umbilical; el día indicado se realizaba el corte con un cuchillo de pedernal que nunca hubiera sido usado y que luego tiraban al río en el que habían bañado al niño; el cordón se cortaba sobre una mazorca de maíz (sobre la cual caía la sangre), que guardaban hasta la primera época de siembra después del nacimiento del niño. Cuando se desgranaba la mazorca se sembraba el grano en el nombre del infante y cuando llegaba la época de cosecha, una parte de la misma se le daba al sacerdote, otra era para hacer las primeras papillas y otra se volvía

${ }^{11}$ Las Casas (1967:vol. II:227)

${ }^{12}$ Torquemada (1975-1983:vol. IV:202)

${ }^{13}$ Ximénez (1930:vol. I:90; Las Casas (1967:vol. II:227)

${ }^{14}$ Fuentes y Guzmán (1969:vol. II:101) 
a sembrar y así cada año hasta que el niño tuviera edad de sembrar por sí solo "diciendo que así no solamente comía del sudor de su rostro, pero de su propia sangre". ${ }^{15}$ Posteriormente se arrojaba el cuchillo de pedernal al mismo río donde días antes habían bañado al niño.

Como podemos observar se pretende un crecimiento paralelo del niño y las cosechas, lo que nos debe hacer recordar la relación estrecha entre hombre y mafz entre los antiguos mayas.

Ritos de infancia

En Yucatán, según Diego de Landa, cuando los niños tenían pocos días de nacidos, sus padres les deformaban el cráneo y para ello utilizaban diversos métodos:

Que las indias criaban a sus hijitos en toda la aspereza y desnudez del mundo, porque a los cuatro o cinco días de nacida la criatura poníanla tendidita en un lecho pequefio, hecho de varillas, y allí, boca abajo, le ponían entre dos tablillas la cabeza: la una en el colodrillo y la otra en la frente entre las cuales se la apretaban tan reciamente y la tenían allí padeciendo hasta que acabados algunos días les quedaba la cabeza llana y enmoldada como la usaban todos ellos. Era tanta la molestia y el peligro de los pobres niños, que algunos peligraban, y el vió agujerarle a uno la cabeza por detrás de las orejas, y así debían hacer a muchos. ${ }^{16}$

\section{En Guatemala:}

El modo de criar los hijos es fajándolos contra una tabla, desde el pecho hasta los pies; por cuya causa todos los indios tienen las cabezas de la parte de atrás llanas y aplastadas. Pende del cabezal de la tabla un arquillo, sobre que ponen un lienzo, que cubriendo el cuerpo de la criatura los defiende de las moscas y polvo y viento. ${ }^{17}$

\footnotetext{
15 Ibid

${ }^{16}$ Landa (1978:54)

17 Fuentes y Guzmán (1969:vol. I:217)
} 
La razón que daba el indígena para la deformación era la siguiente:

Esta costumbre fue dada a nuestros ancestros por los dioses, nos da un aire noble y nuestras cabezas estan mejor adaptadas para llevar la carga. ${ }^{18}$

Los datos anteriores dan por sentado que la deformación craneal se realizaba a todos los nifos y no solamente a los miembros de la nobleza, sin embargo en el Cenote Sagrado de Chichen Itzá se encontraron restos humanos y la relación de cráneos es la siguiente:
a) 13 varones
(entre 18 y 55 años)
b) 7 mujeres
(entre 21 y 34 años)
v) 1 mujer
(entre 35 y 54 años)
d) 1 mujer
(entre 18 y 20 afios)
e) 7 niños
(entre 10 y 13 años)
f) 9 nifios
(entre 4 y 6 anos)
g) 1 nino
(entre 6 y 8 afios)
h) 1 nino
(entre 3 y 4 afios)
i) 1 niño
$(18 \text { meses aprox. })^{19}$

Todos los cráneos muestran trazas de una deformación artificial con excepción de cuatro niños, lo que apoyaría en cierta medida la afirmación de Landa de que todos los nifos sufrian la deformación, aunque hay que tener en cuenta que los cráneos son muy pocos para dar conclusiones.

Los hallazgos muestran que existian varios tipos de deformación craneal:

a) Deformación en el plano occipital

b) Deformación fronto-occipital

c) Depresión en la región post-auricular

d) Deformación post-auricular combinada con aplanamiento frontal

${ }^{18}$ Tozzer (1978:88)

${ }^{19}$ Hooton (1973:273-280) 
e) Deformación frontal con una constricción anular en la region post-coronal

Es más frecuente la deformación frontal que la fronto-occipital que no se encuentra en los cráneos sacados del Cenote. El tipo de deformaciones sugiere que el aplanamiento era acumulado durante el periodo de desarrollo del nifio.

La mayoría de los dioses representados en los codices muestran una deformación craneal; por eso, "adquirir esta fisonomía propia de los dioses era asemejarse a ellos, y con esto, hacer explícito su linaje divino y por tanto, noble".20

El reducido número de cráneos encontrados en las excavaciones, impide dar una respuesta definitiva a si la deformación craneal era una práctica extendida a toda la población como afirma Landa o si era limitada a los miembros de la nobleza, sin embargo, me inclino a pensar que la deformación era practicada por toda la población y que el porte noble del que hablan los textos, es más referencia a un adjetivo que a una jerarqufa social.

En Yucatán las madres también les producian estrabismo a los nifos:

Tenían por gala ser bizcos, lo cual hacían por arte las madres colgándoles del pelo cuando niños, un pegotillo que les llegaba al medio de las cejas; y como les andaba allí jugando, ellos alzaban los ojos y venían a quedar bizcos. ${ }^{21}$

Debemos recordar que el estrabismo es la característica fundamental del Dios G o Dios del Sol, lo que nos hablaría de una posible práctica realizada solo entre los nobles, por lo que es probable que el estrabismo no fuera una práctica común entre los antiguos mayas.

Días después de realizar la deformación craneal, los padres llevaban al niño con el chilam, para que les indicara el oficio que debfa tener la criatura, aś como el nombre que llevaría desde su niffez.

${ }^{20}$ Izquierdo (1983:36)

${ }^{21}$ Landa (1978:54) 
Se pensaba que el curso de la vida de cada individuo era determinado de acuerdo al día del Tzolkín o año sagrado en el que habia nacido. Existía la creencia de que el día del nacimiento influía en el temperamento y destino de la criatura; lo que ejercía una buena o mala influencia en la vida del nifó era el pronóstico del signo del día en que nacía.

Conforme a los libros del Chilam Balam, los pronósticos de los veinte días del calendario ritual eran los siguientes:

1.- KAN........... Sabio

2.- CHICHAN......... Iracundo, Criminal

3.- CIMI............. Criminal

4.- MANIK........... Malo

5.- LAMAT. . . . . . . Borracho, Hablador, Cizafiero

6.- MULUC. . . . . . . Rico, Hipбcrita

7.- OC. ............Adúltero, Cizañero

8.- CHUEN.. . . . . . . . Inteligente, Tejedor, Carpintero

9.- EB. ........... Dadivoso, Bueno

10.- BEEN. . . . . . . Proletario, Plebeyo

11.- IX. . . . . . . Sanguinario, Asesino

12.- MEN.. . . . . . . . Maestro de hacer y de decir.

13.- CIB. . . . . . . . Ladrón, Asesino, Cazador

14.- CABAN.. . . . . . . . Traficante, Curandero, Juicioso, Bueno.

15.- EDZNAB... . . . . . Curandero, Sangrador

16.- CAUAC.. . . . . . . . Imaginativo, Noble

17.- AHAU.. . . . . . . . Rico, Juicioso, Valiente, Bueno.

18.- IMIX.. . . . . . . . . Libidinoso, Indeciso

19.- IK... . . . . . . . . Lascivo, Malo

20.- AKBAL...........Mísero, Plebeyo ${ }^{22}$

El destino individual marcado por el día del calendario sagrado en el que la persona había nacido, podía como entre los nahuas, ser propiciado o cambiado por la acción humana, por lo tanto, el hombre sólo era libre en tanto conocía y dirigía sus determinaciones.

Además del destino individual determinado por el Tzolkín, los antiguos mayas concebfan que las acciones del individuo eran in-

22 Garza (1980) 
fluenciadas por un animal compañero o tona, que acompanaba a la persona toda su vida, desde su nacimiento.

Según Fuentes y Guzmán:

"Que el día que nacía la criatura le daban de ello aviso; anotaba el día de su nacimiento, y en siendo tiempo venía a la casa de los padres del niño: salía la madre con la criatura en los brazos y se la presentaba; íbase con ella detrás de la casa al solar de ella y allí, con muchas ceremonias, invocaba a el demonio, el cual se aparecía si el nifio había nacido a dos de enero, en figura de culebra. Recomendábale el infante para que lo cuidase y defendiese de los peligros: tomaba la mano del chiquillo y poníanla sobre la culebra, en señal de amistad y reconocimiento, y con esto se volvía a su casa, quedando al cuidado de los padres de aquél miserable inocente niño el sacarlo todos los días a la misma hora al solar, donde volvía a salir el nagual; con cuya frecuencia, criándose el niño con aquella ruín y diabólica compañía, le perdía el temor y le acompanaba siempre en todas sus edades". 23

La relación de los días del Tzolkín con los naguales asociados a ellos la describe Fuentes y Guzmán, pero es una cuenta de 31 días en vez de 20 como debería ser, por lo que no es una relación en la que se pueda confiar plenamente.

\section{Imposición del nombre}

El sacerdote que interpretaba el signo del día era el Ah Kin. Durante la infancia los niños llevaban un nombre infantil o paalkaba, que se formaba en Yucatán con la partícula Ah si era varon, e Ix si era mujer y el nombre del animal o planta referido en la predicción del día de su nacimiento. Este nombre lo llevaba el niño hasta que se realizaba la ceremonia de la unción o caputzihil. A partir de esta ceremonia llevaban el nombre de los padres hasta que se casaban, a partir de lo cual se llamaban por el nombre del padre y de la madre. ${ }^{24}$

${ }^{23}$ Fuentes y Guzmán (1969:vol. I:280)

${ }^{24}$ Landa (1978:58) 
En el calendario indígena cada día tiene un nombre que consiste en la combinación de un signo (20) y un numeral (13) por lo que hay un total de 260 nombres.

Según Landa:

Los nombres de los padres duran siempre en los hijos; en las hijas no. A sus hijos e hijas los llamaban siempre por el nombre del padre y de la madre; el del padre como propio y el de la madre como apelativo; de esta manera, el hijo de Chel y Chan llamaban Nachanchel, que quiere decir hijos de fulanos y esta es la causa (por la cual) dicen los indios que los de un nombre son deudos y se tratan por tales. Y por eso cuando vienen a parte no conocida (y se ven) necesitados, acuden luego al nombre, y si hay alguien (que lo lleve), luego con toda caridad se reciben y tratan. Y así ninguna mujer u hombre se casaba con otro del mismo nombre porque en ellos era gran infamia. ${ }^{25}$

Contrario a lo que Landa señala, Roys dice que las hijas y los hijos reciben el nombre del padre, las mujeres lo retienen hasta después del matrimonio y establece que existen varios nombres para cada persona:

a) El patronímico o nombre familiar, heredado en linea paterna.

b) Nombre materno que viene a través de la madre: Naal

c) Nombre del infante que precede al nombre familiar o Paalkaba.

d) Apodo o Coco-kaba

e) Título de rango u ocupación

En Guatemala el nombre consistía en:

a) Apellido y nombre calendárico

b) Título y nombre calendárico

c) Título, apellido y nombre calendárico

d) Título y clan de linaje

e) En raras ocasiones se combinaba el apellido y el nombre individual, así como el nombre individual con el nombre calendárico. ${ }^{26}$

${ }^{25}$ Landa (1978:41-42)

${ }^{26}$ Roys Ralph (1940:5-30) 
El acto de imposición de nombre es de suma importancia para la creación de la personalidad; poner nombre significa dar poder, conferir una determinada personalidad o alma; mediante él es puesto el niño en conexión con su ascendencia divina y humana, a la vez que recibe un lugar en la sociedad. La ceremonia de imposición de nombre a veces forma parte de los ritos de pubertad o puede posponerse hasta que se obtiene algún signo mediante la astrología o la adivinación.

Dado que el nombre guarda relacion muy estrecha con la personalidad y la condición social del individuo, su imposición no queda confinada en las primeras etapas de la vida, sino que a lo largo de ella un hombre o una mujer pueden cambiar de nombre muchas veces, según lo pidan las circunstancias.

En Guatemala cada una de las etapas de la vida del niño se festejaba con un convite y sacrificios a los dioses, asi, Fuentes y Guzmán afirma que:

Quitados del pecho, desde que los desmamantan, aunque sean hijos de caciques $o$ ahagues no permiten que coman otro manjar que el pan de maíz, tamal o tortilla, ni la madre mientras los cría, come ni gusta otro manjar, aunque tenga carnes de vaca o venado, tepesquintle 0 otras, y cuando mucho, añade a el apetito una poca de sal o el revoltillo de chile y tomate que llaman chilmole. ${ }^{27}$

Este pequeño fragmento nos muestra que en la época del destete, tanto la madre como el hijo solamente se alimentaban de maíz, el cual había sido el principal alimento de la madre mientras criaba al niño, lo que podría indicar implicaciones simbolicas ya que se concibe al niño como hombre de maíz.

Al adquirir cierta individualidad con el destete, el niño entraba en una etapa de su vida que se representará por un ritual preparatorio para la pubertad y que se mostrará por la imposición de cuentas y conchas.

${ }^{27}$ Fuentes y Guzmán (1969:vol. I:221) 
Landa indica que cuando se destetaba al niffo:

... a los varoncillos usaban siempre ponerles pegada a la cabeza, en los cabellos de la coronilla, una contezuela blanca, y a las muchachas traíanlas centidas abajo de los rifiones con un cordel delgado y en él una conchuela asida, que les venía a dar encima de la parte honesta y de estas dos cosas era entre ellos pecado y cosa muy fea quitarla de las muchachas antes del bautismo...28

En la Relación de Motul, se dice que la concha de las niñas son rojas. Tanto las conchas como las piedras tienen un significado de pureza sexual y por eso no debían quitárselas antes de la ceremonia de la unción.

\section{Rito de pubertad}

El pensamiento del maya antiguo era rico en simbolismos, por lo que el individuo en el transcurso de su vida sufría varias transformaciones tanto sociales como religiosas, marcadas por los llamados ritos de pasaje. El mejor ejemplo de este tipo de rituales es una ceremonia que realizaban los mayas yucatecos en el siglo xvı y que Fray Diego de Landa llamo bautismo. ${ }^{29}$

El caputzihil, que significa "nacer de nuevo" era un ritual del ciclo de vida que se efectuaba durante una fiesta llamada emkú o "bajada de dios". Como sus nombres lo indican, tanto el ritual como la fiesta implican la transformación de los participantes a causa de la inmanencia de lo divino; este tipo de renovación se practicaba una vez en la vida y nadie dejaba de recibirlo, se efectuaba a todos los niños entre los tres y los doce años y era indispensable para contraer matrimonio posteriormente. Se decía que se realizaba para que los niños contaran con la protección de los dioses y así se evitara el daño de entidades malignas.

Los padres de los niños que iban a participar en la ceremonia ayunaban y se abstenían sexualmente tres días antes de realizarla

${ }^{28}$ Landa (1978:44)

29 Landa (1978:44-47) 
con el objeto de propiciar a las divinidades. Esta ausencia de placer físico y la no satisfacción de las necesidades, ayuda a la inmanencia de lo sagrado.

Un sacerdote echaba suertes para ver cual era el día propicio para realizar la fiesta y a continuación lo anunciaba a toda la comunidad.

El padre de uno de los iniciandos elegía a un principal del pueblo para que le ayudara a subvencionar los gastos de la fiesta y se seleccionaban cuatro ancianos a los que denominaban chaques, para que ayudaran al sacerdote en la ceremonia durante la misma.

El día de la celebración, se reunían los participantes en una casa y llevaban a los iniciandos a un patio cubierto con hojas frescas de cihom (Sapindus saponaria), donde los separaban en dos hileras una para niñas y otra para niños, las primeras tenfan como madrina a una anciana y los segundos a un hombre adulto. Se procedia entonces a la purificación de la posada eliminando el mal de la misma, para ello se ponían cuatro banquillos en las esquinas del patio en los cuales se sentaban los cuatro chaques con un cordel asido por cada uno, de manera que quedaban los niños dentro de un espacio delimitado; después, pasando sobre el cordel, entraban todos los padres de los niños. A continuación ponfan en el centro del patio un banco donde el sacerdote se sentaba con un brasero y un recipiente con un poco de maíz molido e incienso, pasaban los niños uno por uno ante el sacerdote, quien se los daba y ellos lo echaban en el brasero. Cuando todos los niños habían pasado, el sacerdote tomaba el brasero junto con el cordel que delimitaba el patio y un poco de balché, y se los daba a un miembro de la comunidad para que los llevara fuera del pueblo, advirtiéndole que no podía beber este líquido sagrado ni mirar hacia atrás mientras se alejara y con esta expiación se decía que el mal se había ido. Una vez que aquél se había alejado, se quitaban las hojas del patio y se colocaban otras de un árbol al que llamaban copó y se extendían unas esteras en el piso. En ese momento salía el sacerdote y se sentaba en el centro del patio en una estera, mientras los chaques colocaban paños blancos en la cabeza de cada uno de los iniciandos quienes al pasar junto al sacerdote eran bendecidos por éste. El ofi- 
ciante al terminar le daba un hueso al principal quien tocaba nueve veces en la frente a cada niño y después los ungía con agua en la cara y entre los dedos de pies y manos sin decir una sola palabra.

Para la unción se utilizaba agua de los montes en la que diluían cacao mezclado con flores, llamándola "agua virgen"; al terminar el sacerdote les quitaba a los niños los paños blancos y se los daba a uno de los chaques, después les cortaba la cuenta que sus padres les habfan pegado en la coronilla desde la infancia; tras esto, iban los ayudantes del sacerdote con un manojo de flores y golpeaban con él nueve veces a cada niño y después les daban a oler flores y a chupar un humazo.

Al terminar la ceremonia se recogían las viandas que llevaban las madres de los niños y se organizaba una comida donde ofrendaban alimento a las divinidades, rogándoles que recibiesen ese pequeño don de parte de los iniciandos.

A uno de los oficiantes al que llamaban cayom le daban a beber el balché que sobraba y se lo tomaba sin descansar, ya que lo contrario se consideraba una falta contra los dioses; al final, las madres les quitaban a las nifias la concha que traían sobre el pubis atada a su cintura como símbolo de virginidad, lo que les daba la oportunidad de casarse cuando los padres lo decidieran.

Al irse los niffos y sus madres, los padres repartían mantas entre los oficiantes terminando la fiesta con un convite. Por último, el principal que la había organizado se abstenía sexualmente por nueve días más.

Como podemos apreciar, los mayas yucatecos concebían la presencia de Dios durante la fiesta y por eso se debía buscar la pureza ritual a través del ayuno y la abstención sexual previa a la ceremonia, dividiendo asi dos tiempos, uno profano y otro sagrado, propicio este último para tener contacto con los dioses.

En la cosmovisión maya yucateca, la presencia de los dioses en la ceremonia requiere de un ritual propiciatorio que juega el papel de aglutinante social.

La limitación del patio, con la consiguiente purificación, lo transforma simbolicamente en un espacio sagrado, en un centro 
del mundo ya que los cuatro chaques, colocados en las esquinas del patio muy probablemente representaban a las cuatro deidades que en la cosmología maya se situaban en las esquinas de las regiones cosmicas. Este espacio ya sacralizado se encuentra totalmente aislado de la realidad cotidiana y crea una dicotomfa existencial que se ve confirmada con el ritual expiatorio cuando junto con el brasero se van todas las faltas de los iniciandos, purificándolos por este mismo acto. Así se cumple con la primera parte del rito de pasaje que implica la separación del grupo o el individuo, de su anterior situación dentro de la estructura social o de un conjunto de condiciones culturales.

El sacerdote que preside la ceremonia portaba un atavío que según Landa consistía en:

Un saco de plumas coloradas y labrado de plumas de colores y otras plumas largas colgando de los extremos (del saco) y una como corona, de las mismas plumas, en la cabeza, y debajo del saco muchos listones de algodón (que llegaban) hasta el suelo, como colas, y con un hisopo en la mano, hecho de un palo corto muy labrado y por barbas y pelos del hisopo ciertas colas de una culebra (que son) como cascabeles. ${ }^{30}$

El poder regenerativo y transformador de las colas de serpiente del hisopo, bien podrían simb6licamente llevar a los iniciandos a la etapa liminar del ritual mediante la bendición del sacerdote.

Se ayudaba a velar la identidad del individuo mediante los paños blancos en la cabeza de los nif́os, asi, cuando el principal tocaba nueve veces con un hueso la cabeza de cada uno, traspasaba todos y cada uno de los diversos niveles que conformaban el inframundo de los mayas yucatecos, logrando asf la muerte simb6lica de los iniciandos.

Lo anterior constituía la etapa liminar y se iniciaba la de agregacion al ungirles "agua virgen", lo que implicaba un nuevo nacimiento con la total transformación del niño en adulto, reconfirmado por la eliminación de los paños blancos y de las cuentas que

${ }^{30}$ Landa (1978:45-46) 
trafan en la cabeza que representaban la etapa infantil de los muchachos; el cambio completo se lograba con la imposición del nombre, que muy probablemente les daba el sacerdote al quitarles la cuenta de la coronilla.

Landa dice que en esta ceremonia se le impone un nuevo nombre al nifio, sin embargo cuando lo describe no aclara en que momento de la ceremonia se realizaba, lo más probable es que se llevara a cabo mientras unglan al niño.

Al atravesar los nueve niveles hacia su nueva realidad con sendos golpes que los ayudantes del sacerdote daban con el manojo de flores, se terminaba la etapa de agregación que es la última fase del ritual, alcanzando un nuevo estado a través del rito, con los que los iniciandos adquirfan derechos y obligaciones de tipo estructural dentro de la sociedad.

El mismo estado alcanzaban las nifias cuando sus madres les quitaban la concha que trafan colgada de la cintura, símbolo de virginidad y pureza, logrando así una transformación con la que la nifia adquiere un rango social superior. El caputzihil era por tanto, uno de los ritos del ciclo de vida del maya yucateco indispensable para quién lo vivia, asf como para la comunidad que lo realizaba.

El caputzihil simboliza una transformación en el nif́o y tiene un significado religioso que debe hacerse notorio al grupo donde se desarrollara posteriormente. Como todo rito de pubertad, es muy probable que sea una etapa por la que pasaban todos los nifios de la comunidad y no sólo los miembros de las clases nobles.

\section{Rito de matrimonio}

Durante la Colonia no existra entre los mayas el noviazgo propiamente dicho pues los padres de los contrayentes eran quienes concertaban el matrimonio; el padre de la muchacha nunca se preocupaba por casar a su hija, en vez de eso, esperaba que la fueran a pedir.

En Yucatán la edad de los futuros contrayentes fluctuaba entre los doce y los veinte años. ${ }^{31} \mathrm{El}$ padre del novio escogfa una mujer para su hijo, que fuera de la misma localidad y condición social.

${ }^{31}$ Landa (1978:42) 
Las costumbres matrimoniales de los mayas yucatecos están referidas fundamentalmente por Landa quien dice que:

... muchos había que nunca habían tenido sino una (mujer) la cual ninguno tomaba (en la familia) del padre, porque era cosa muy fea entre ellos; y si alguno se casaba con las cufnadas, mujeres de sus hermanos, era tenido por malo. No se casaban con sus madrastras ni cuñadas, hermanas de sus mujeres, ni tías, hermanas de sus madres, y si alguno lo hacía era tenido (por) malo. Con todas las demás parientes de parte de su madre contrafan (matrimonio), aunque fuesen su prima hermana. ${ }^{32}$

Lo anterior nos muestra que no se practicaba el levirato ni el sororato.

Para tratar el matrimonio concertaban la dote que daba el padre del novio al consuegro, de donde la madre del novio hacía vestidos para él y para la nuera.

El día de la boda se hacía un banquete en casa del padre de la novia, donde el sacerdote se aseguraba de que los suegros estuvieran de acuerdo. Esa noche se le entregaba la novia al novio y luego se hacía una comida, de ahí en adelante el novio trabajaba de cinco a seis años para el suegro y si no lo hacía lo echaban de la casa.

Al terminar el tiempo de trabajo acordado con la familia de la mujer, había dos opciones además de seguir viviendo con los parientes de la esposa: ir a formar parte del grupo del padre del novio o abrir nuevas tierras al cultivo y establecerse independientemente. Sembraban para cada pareja una parcela de tierra que llamaban hum uinic que medía 400 pies cuadrados. ${ }^{33}$

Entre los viudos, el matrimonio se consideraba automático en el momento en el que la mujer admitía al hombre en su casa y le daba de comer, aunque siempre se esperaban un año después del fallecimiento de su primer consorte.

Entre los quichés se segura una exogamia patrilineal como lo indica el texto de Las Casas:

${ }^{32}$ Landa (1978:43)

${ }^{33}$ Landa (1978:40) 
Casábanse con todos los grados de consanguinidad de la manera dicha, porque más por hermana tenían la de su linaje... que la hija de su madre con que fuese de otro marido, y... Casábanse con los cufiados que tuviesen hijos y no los tuviesen. Casábanse también con las madrastras por alguna causa que tenían... y sin que por ello se hiciese castigo o diese pena. ${ }^{34}$

Entre la gente común, quien pedía a la novia era el padre del novio, un hermano o un pariente cercano.

Entre los principales, el padre del novio elegía a la novia y la compraba dándole al consuegro una dote, consistente en cuentas de piedras preciosas y "hojas de guanín que era cierta especie de oro bajo que ellos olían y tenían por joyas preciosas, para ponerse colgadas de las orejas". ${ }^{35}$ Una dote cuantiosa podía consistir en oro, plumas, cacao o gallinas.

Si los novios pertenecfan a familias importantes, todos los súbditos y parientes contribuían según sus posibilidades para la dote. Si al padre de la novia no le interesaba la unión, no recibía los presentes y daba alguna excusa; en cambio si aceptaba, era entendido que se acordaba el matrimonio. La aceptación se hacfa generalmente después de dos o tres veces que el padre del novio enviaba presentes a su consuegro. Desde el momento en que aceptaban los presentes se trataban como familiares y se hacian los vestidos de los novios.

Según Fuentes y Guzmán el novio trabajaba un año para su futuro suegro antes del matrimonio; si se desbarataba el compromiso el padre de la novia le reintegraba los presentes que hubiera dado y trabajaba para la familia del novio el mismo tiempo que había trabajado este último.

El día de la boda el padre del novio enviaba a casa de su consuegro varios presentes; se realizaba una fiesta de despedida y al terminar se formaba el cortejo para acompañar a la novia a casa de su suegro; el padre del novio enviaba mujeres ancianas y

${ }^{34}$ Las Casas (1967:vol. II:517)

${ }^{35}$ Las Casas (1967:vol. II:518) 
principales para acompafiar a la novia y para ello la cargaban en hombros "aunque estuviera muy lejos".

Los principales llevaban a la novia a un lugar previamente elegido donde ciertos hombres honrados, enviados por el suegro, ofrecian incienso delante de la novia y ofrendaban codomices a sus dioses, dando gracias por la llegada de la novia. Cuando ésta llegaba a casa de su suegro la ponfan en un tálamo bien aderezado y se hacía una fiesta con bailes y cantos.

El sacerdote corroboraba la compatibilidad de los signos bajo los cuales habían nacido los futuros cónyuges y elegfa el día favorable para la celebración del matrimonio.

La ceremonia religiosa se celebraba en casa del principal de donde eran los novios, quienes al llegar confesaban sus faltas. El anciano que los casaba ataba los cabos de las mantas que los cubrian y los exortaba a que fueran agradecidos con sus dioses; los parientes les obsequiaban presentes y se incensaba la casa, terminando el ritual bendiciendo a los novios con varias oraciones. Según Fuentes y Guzmán, dos ancianos cargaban en hombros a los novios y los conducfan a su nueva casa mientras el cortejo tiraba flores por donde pasaban. Los acostaban al llegar a la casa y los dejaban encerrados; en la noche, dos mujeres ancianas los metian en una pieza y les ensefiaban como habfan de tratarse en el matrimonio.

Los parientes, después de que los novios se quedaban en su casa, comían y bebian "conforme al posible de los novios" y si los conyuges eran caciques, el banquete duraba varios días.

El matrimonio implica la adopción de los protectores ancestrales del novio por parte de la novia, por lo que muchas veces este tipo de alianzas provoca la pérdida de identidad de la contrayente quien abandona por completo su medio para entrar a otro donde se le considera extraña hasta el momento del matrimonio.

Entre la gente común, los padres iban a buscar mujeres para sus hijos llevando maíz en señal de lo que el novio tenfa de hacienda. La madre del novio iba por la novia y la llevaba a su casa donde "un hijo del pueblo" los casaba y los exortaba a que formaran un buen matrimonio. 
Por lo general la dote que llevaban era el precio de la novia, quien jamás volvía a casa de su padre aunque fuera viuda porque habia levirato y si no se casaban con su curfado lo hacian con cualquier pariente del difunto. ${ }^{36}$

Según Las Casas, cuando se casaba el hijo de un Señor con una nif́a menor de edad, los parientes de ésta le daban una esclava o dos mientras la niña crecía.

La etapa final del matrimonio se celebra con signos de júbilo que frecuentemente incluyen una procesión solemne y siempre se acompaña de una alegre fiesta nupcial. El desenfreno que tan frecuentemente se daba era resultado, en gran parte, de las estrechas relaciones entre iniciacion y fecundidad.

\section{Ritos funerarios}

\section{a) Yucatán}

Las prácticas funerarias pueden aportar datos sobre las creencias escatologicas de los mayas prehispánicos. En Yucatán se enterraba a los muertos amortajando el cuerpo y llenándole la boca de mafz molido y algunas piedras de jade de las que tienen por moneda, y se decía que aquello era para que en la otra vida no les faltara de comer; podemos entender que el maíz servía de alimento y el jade para comprarlo en la siguiente existencia, pero también se puede entender que el maí, como símbolo de vida se les colocaba en la boca como elemento vital, lo que implicaría la creencia en una escatología en espejo.

La gente pobre era enterrada bajo el piso de su casa o atrás de ella, y les echaban en la sepultura los f́dolos familiares, se dice que estos abandonaban la casa a menos que hubiera mucha gente viviendo en ella en cuya compañia perdían el miedo.

Los f́dolos que acompañaban al difunto tienen dos funciones, la primera sería la de servir como protección mágica y por otra confirma la escatologia en espejo pues servirfan como protectores familiares en la otra vida, es decir, podemos pensar en la creencia en una vida posterior semejante a esta.

${ }^{36}$ Ximénez (1965:vol. I:97) 
A los grandes sefiores los incineraban y ponfän sus cenizas en grandes vasijas sobre las cuales se edificaban pequefios templetes.

En ocasiones se elaboraban estatuas de madera a las cuales les dejaban un agujero en la coronilla, quemaban alguna parte del cuerpo del difunto y esas cenizas las colocaban dentro de la estatua tapando el agujero con la piel de la coronilla del difunto, posteriormente enterraban el resto del cuerpo y guardaban esas estatuas como uno de sus dioses, lo que nos demostraría la probable deificación de los seffores y la estrecha relación de lo divino con la nobleza.

A los señores Cocom se les cortaba la cabeza, la cocian, la limpiaban y le aserraban la parte posterior, a estas medias calaveras las rellenaban con algun betún y las guardaban en las casas $\mathrm{u}$ oratorios junto con sus dioses y en todas sus fiestas les hacian ofrendas alimenticias para que no les faltaran en la otra vida.

A los sacerdotes se les enterraban con sus codices, a los hechiceros con sus piedras de hechizo, es decir, acompañaban al difunto sus más representativas pertenencias.

Según Landa la vida futura se dividía en buena, para los que llevaron una vida positiva y la mala para los viciosos; es de esperarse que esos conceptos sean más de la mente cristiana que de la indígena.

\section{b) Guatemala}

Cuando algún principal se enfermaba, lo primero que hacfan era llamar al sacerdote que trataba de curarlo con hierbas, posteriormente se llamaba al astrologo para que dijera qué tipo de sacrificio sería el más propicio y agradable a los dioses para ofrecerlo por la salud del señor. Algunas veces sacrificaban aves de colores y llegaban a realizar sacrificios humanos en el caso de una enfermedad grave, en la mayoría de los casos se sacrificaba a un hijo legítimo pero sólo en el caso de que vivieran varios hijos que pudieran heredar.

$\mathrm{Al}$ acabar los sacrificios el enfermo confesaba sus pecados considerando primordialmente las faltas de tipo sexual, como el adulterio o el haber quebrantado ayunos o abstenciones sexuales pre- 
vias a las fiestas; la confesion la realizaban como ritual expiatorio $\leftarrow$ y si ésta no daba resultado para curar al enfermo, poco antes de expirar se le colocaba una piedra preciosa en la boca para que recibiera su alma y al morir se la pasaban por el rostro como último recurso para devolverle la vida. Posteriormente la piedra era consideraba divina y le ofrecfan sacrificios en sus fiestas y al difunto se le deificaba. ${ }^{37} \mathrm{Si}$ se le ofrecían sacrificios a la piedra tal vez era porque la esencia del difunto pasaba a ella.

Al morir el sefior se enviaban mensajeros a los pueblos sujetos y a los demás sefiores, pidiéndoles que acudiesen al entierro.

Adomaban el cuerpo con las mejores vestiduras, joyas de oro y piedras preciosas que el mismo difunto habia recolectado en vida para que fueran sus companferas en la tumba. Colocaban el cadáver sentado sobre un estrado y lo velaban varios días en un lugar público, mientras llegaban los Seffores y vasallos quienes le llevaban al difunto piezas de oro y ricos vestidos, a la vez que varios esclavos para sacrificarlos y que le sirvieran al Señor en su vida futura.

A los esclavos les daban sus instrumentos de labranza, arcos, flechas y a las esclavas las piedras con que habfan de moler el maiz y todas las ollas, vasijas y cántaros que usarfan para servir a su señor.

Colocaban al difunto en cuclillas en una caja de piedra o madera que depositaban en un hoyo cavado en la cumbre de una montana, sacrificaban alrededor a los esclavos, cubrian los restos y haćan un pequefio altar de cal y piedra en el cual quemaban incienso y ofrecian sacrificios durante sus fiestas. ${ }^{38}$

Cuando no habfa caja de piedra o de madera, cavaban un hoyo en la tierra y en sus paredes hacian una pequeña cueva donde colocaban el cuerpo sentado; despues lo llenaban con tierra de manera que ésta no tocara la cara del difunto. ${ }^{39}$

Las Casas nos describe una forma de sepultura muy especial y que s6lo se realizaba para los difuntos que fueran señalados reyes. ${ }^{40}$

37 Las Casas (1967:vol. II:525)

38 Las Casas (1967:vol. II:526)

39 Ximénez (1965:vol. I:100)

40 Las Casas (1967:vol. II:527) 
Quemaban el cuerpo del difunto y de los huesos y cenizas que quedaban formaban un cuerpo, uniendo las partes del mismo con un hilo de oro $\tan$ grueso como se suele hacer de hierro; ligaban los dedos de los pies y de las manos y en cada uno ponfan una piedra preciosa lo mismo que en la nariz.

Al terminar de hacer el cuerpo se echaban suertes para saber la hora, el día y el lugar del entierro inquiriendo la voluntad de los dioses, posteriormente el cuerpo se colocaba en una caja de piedra o madera y le tenían gran veneración a tal grado que le ofrecían sacrificios igual que a sus dioses.

Por su parte, Fuentes y Guzmán dice que cuando una persona moría se lavaba el cadáver con un cocimiento de hierbas y flores aromáticas, se vestía el cuerpo con ropas finas y lo colocaban en un tablado sobre paños labrados de chuchumite; en la noche se le llevaba oro, plata, mantas, petates, plumas, papagayos, guacamayos, maíz, came y carbón. Colocaban el cadáver sobre el sepulcro mientras los sacerdotes decían oraciones, ponían el cuerpo dentro de una olla de barro al igual que las ollas y las plumas, lo demás lo ponfan junto a la olla tapada y luego cubrían con tierra la fosa, después levantaban un cerrillo de piedra y lodo sobre el cual ponían una estatua que simbolizaba al señor y le ofrendaban flores, aves, conejos, etc. y ese cerro con la estatua eran considerados sagrados. Si el difunto habfa sido rey, el lugar quedaba como adoratorio y si habfa sido principal se convertfa en lugar de refugio para delincuentes. Después del entierro se celebraba un banquete en casa del difunto donde asistían los principales, los criados nobles, los criados inferiores, todos se embriagaban y se sacrificaban varios animales.

Por supuesto, lo anterior s6lo lo realizaban los miembros de las clases altas, en cambio, quienes no tenían posibilidades económicas, hacían una sepultura y en una de sus paredes cavaban una pequeña cueva donde metían el cuerpo del difunto y lo sentaban, echaban tierra pero el cuerpo no era tocado por la misma. El mismo autor nos dice que antiguamente se enterraban también en las milpas y levantaban montículos de tierra conforme a la grandeza del occiso. 
Como podemos observar, los ritos de pasaje son una de tantas respuestas que el hombre ha elaborado para responder a sus cuestionamientos existenciales, derivados de la conciencia de su mortalidad; son uno de los medios de acercamiento al mundo escatologico inmerso en el hombre, es por eso que conforman una unidad dentro de la mentalidad simb6lica del hombre.

\section{BIBLIOGRAFIA}

AcOSTA, JOSEPH DE

1979 Historia Natural y Moral de las Indias, Fondo de Cultura Económica. México

AgUtrRe Beltran, Ignacio

1963 Medicina y Magia. El proceso aculturación en la estructura colonial, Instituto Nacional Indigenista.

Avendaño y Loyola, Fray ANDRés

1917 Relación de las dos entradas que hizé a Petén Ytzá, en Ains worth Means Philip, History of Yucatan and of the Itzas, Papers of the Peabody Museum of the American Archaeology and Ethnology, vol. VII, Harvard University.

BARRERA RUBIo, ALFREDO

1973 "Evolución del sacerdocio maya en la península de Yucatán" Boletín de la Escuela de Ciencias Antropológicas, año 1 No. 3, pp 7-23, Universidad de Yucatán, Mérida.

BeNAVIDES, ANTONIO

1976 "Algunos espacios sagrados y deidades del occidente de Yucatán", Boletín de la Escuela de Ciencias Antropológicas, año 4 No. 16, pp. 19-28, Universidad de Yucatán, Mérida.

BLeEkER, C. Y G. WIDENGREN

1975 Historia Religionum. Manual de Historia de las religiones Cristiandad, Madrid.

Cardin, Franco

1982 Magia, Brujería y Superstición en el Occidente Medieval, Ed. Península, Barcelona.

Ciudad Real, Antonio de

1976 Relación Breve y Verdadera... 2 vol. Serie de historiadores 
y cronistas de indias \# 6, Instituto de Investigaciones Históricas, UNAM, México.

Códices Mayas. Dresdensis,

Peresianus, Trocortesiano

1933 Interpretación de J. A.Villacorta, Sociedad de Geografía e Historia de Guatemala, Tipografía Nacional, Guatemala.

Cortés y LaRraz, Pedro

1983 Descripción Geográfica moral de la diócesis de Guatemala, 2 vols. Biblioteca Goathemala \# XX, Guatemala.

Chi, Gaspar Antonio

1975 "Relación" (1582), Landa's Relación... de Tozzer pp. 230232, Papers of the Peabody Museum of American Archaeology and Ethnology, Harvard Univeristy, KraussR e pri in t, Co. Willwood, New York.

El Libro de los Libros de Chilam Balam

1969 Traducción de Alfredo Barrera Vázquez, Fondo de Cultura Económica, México.

El Chilam Balam de Chumayel

1985 Traducción de Antonio Médiz Bolio, Secretaría de Educación Pública, México.

Fox, RoBIN

1979 Sistemas de Parentesco y Matrimonio, Alianza Universidad, Madrid.

Fúntes y GUZMÁN, ANTONIO DE

1969 Recordación Florida... 3 vols. Biblioteca de Autores Espanoles. Obras Históricas de F. A. de Fuentes y Guzmán. Ed. Atlas, Madrid.

Garza, Mercedes de LA

1978 El hombre en el pensamiento náhuatl y maya, Centro de Estudios Mayas, UNAM, México.

1980 Literatura Maya, Biblioteca Ayacucho, Espafia.

Gómez Canedo, Lino

1977 Evangelización y conquista: experiencia franciscana en Hispano-América, Porrúa, Mexico.

HERMITTE, EsTHER

1970 Control social y poder sobrenatural en un pueblo maya contemporáneo. Ed. especiales Instituto Indigenista Interamericano, No. 57, México.

Hooton, EARNEST A.

1973 "Skeleton from the Cenote of Sacrifice at Chichen Itza", The Maya and their Neighbors, pp. 272-280 
Landa, Fray Diego de

1978 Relación de las cosas de Yucatán, Porrúa, México.

Las Casas, Fray Bartolome de

1967 Apologética historia sumaria, Edición de Edmundo

O'Gorman, 2 vols. Instituto de Investigaciones Históricas, UNAM, México.

Lizana, Fray Bernardo de

1893 Historia de Yucatán. Devocionario de Nuestra Señora de Izamal y Conquista Espiritual, Imprenta del Museo Nacional, México.

LOPEZ Cogolludo, Diego

1971 Los tres siglos de la dominación española en Yucatán... 2 vols. Akademische Druck-u Verlagsanstalt, Graz, Austria.

LOPEZ MedeL, TOMAS

1941 "Relación" en Landa's Relación de las cosas de Yucatán, de A. Tozzer, Papers of the Peabody Museum of American Archaeology, Harvard University, Cambridge.

Morley, Sylvanus G.

1972 La civilización maya. Fondo de Cultura Económica. México.

Remesal, ANTONIO DE

1963 Historia general de las Indias Occidentales y particular de la gobernación de Chiapas y Guatemala, Ed. José de Pineda Ibarra, 4 vols. (Biblioteca Guatemalteca de Cultura Popular, vols. 91-94) Guatemala C.A.

ROMÁN Y ZAMORA, Fray JerónImo de

1897 República de Indias... (Col. de libros raros y curiosos que tratan de América XIV-XV), Victoriano Suárez Editor, Madrid.

ROYS, RALPH

1972 The Indian Background of Colonial Yucatan, Carnegie Institution of Washington, Washington D.C.

TOZZER, Alfred

1975 Landa's Relación de las cosas de Yucatán, Papers of the Peabody Museum of American Archaeology and Ethnology Harvard University. 